\title{
Editorial
}

\section{Aspectos bioéticos del aborto en Chile}

En el N ${ }^{\circ} 4$ de 2013 de la Revista Chilena de Obstetricia y Ginecología se ha invitado a dos destacados profesores para que editorialicen sobre "Aspectos bioéticos del aborto en Chile". Ellos son los especialistas en Ginecología y Obstetricia Drs. Ramiro Molina Cartes (Facultad de Medicina, Universidad de Chile) y Mauricio Besio Rollero (Facultad de Medicina, Universidad Católica de Chile). Ambos aceptaron desarrollar el tema y fueron convocados en conocimiento de su mutua participación, desconocimiento del documento contrario, una extensión de 2000 palabras y publicación del documento en su versión original y sin cambios editoriales.

Chile es uno de los pocos países del mundo que penaliza el aborto en cualquier circunstancia. El artículo 119 del Código Sanitario desde 1989 establece: "No podrá ejecutarse ninguna acción cuyo fin sea provocar un aborto" (1); además el artículo 19 de la Constitución Política establece que: "La ley protege la vida del que está por nacer" (2).

El 17 de noviembre de 2013 se realizará la primaria de la elección presidencial y las diferentes candidaturas se han pronunciado en sus plataformas programáticas sobre la despenalización del aborto terapéutico, eugenésico y por violación. Es necesario que la comunidad médica y muy especialmente los encargados del cuidado de la salud sexual y reproductiva, que tengamos un profundo conocimiento sobre este tema en sus aspectos bioéticos, legalidad actual y los posibles cambios en la despenalización del aborto. Para ello podemos encontrar los proyectos de ley presentados en la página web de la Cámara de Diputados de Chile en sus diferentes estados de tramitación (3), como también los aspectos relevantes sobre la despenalización del aborto resumido por la Biblioteca del Congreso Nacional de Chile (4) que se presenta en extenso en la sección CRÓNICA de este número. Los invito a leer con detención los documentos de estos destacados profesores.

Dr. Enrique Donoso S. Editor Jefe. Revista SOCHOG.

\section{REFERENCIAS}

1. Código Sanitario, República de Chile. Libro V. Del ejercicio de la medicina y profesiones afines. Artículo 119. Ley № 18.826 del 15 de septiembre de 1989.

2. Constitución Política de la República de Chile. Decreto Supremo № 1.150 de 1980. Disponible en: http:// www.paginaschile.cl/biblioteca_juridica/constitucion. htm.

3. CámaradeDiputadosdeChile.ProyectosdeLey.http://www. camara.cl/pley/pley_buscador.aspx?prmBuscar=aborto

4. Biblioteca del Congreso Nacional de Chile. Aborto terapéutico: hitos legislativos. http://www.bcn.cl/carpeta_temas_profundidad/aborto-terapeutico-hitoslegislativos. 